\title{
Effects of Colorectal Cancer Risk Factors on the Association Between Aspirin and Colorectal Cancer
}

\author{
MAX E. SEATON ${ }^{1}$, ULRIKE PETERS ${ }^{2,3}$, KAREN C. JOHNSON ${ }^{4}$, \\ CHARLES KOOPERBERG ${ }^{3}$, ANDREA BAFFORD ${ }^{1}$ and NIHA ZUBAIR ${ }^{3}$ \\ ${ }^{1}$ Department of Surgery, University of Maryland Medical Center, Baltimore, MD, U.S.A.; \\ ${ }^{2}$ Department of Epidemiology, University of Washington, Seattle, WA, U.S.A.; \\ ${ }^{3}$ Division of Public Health Sciences, Fred Hutchinson Cancer Research Center, Seattle, WA, U.S.A.; \\ ${ }^{4}$ Department of Preventative Medicine, University of Tennessee Health Science Center, Memphis, TN, U.S.A.
}

\begin{abstract}
Background/Aim: We investigated the effect of aspirin on colorectal cancer (CRC) risk among subgroups of women with and without risk factors for CRC. Patients and Methods: Using data from the Women's Health Initiative, we estimated hazard ratios for CRC in association with aspirin use, with stratifications by cardiovascular disease (CVD) risk status, family history of CRC, and history of colorectal polypectomy. Results: Aspirin was associated with a lower risk of CRC among women with low/normal or high CVDrisk status; no family history of CRC; or a history of colonoscopy with polypectomy. Aspirin was not associated with CRC among women with a family history of CRC or a history of colonoscopy without polypectomy. Conclusion: Aspirin was associated with a lower risk of CRC in women at all levels of CVD-risk, in those with a history of colonoscopy with polypectomy, and in those without a family history of CRC.
\end{abstract}

Colorectal cancer (CRC) is one of the most common and fatal cancers, with approximately 1.8 million new cases and 862,000 deaths worldwide in 2018 (1). Numerous studies have established that regular aspirin use lowers the risk of CRC (2-5). However, long-term aspirin therapy is associated with several complications, including gastrointestinal and intracranial hemorrhage $(6,7)$. Furthermore, aspirin use

This article is freely accessible online.

Correspondence to: Max E. Seaton, MD, Department of Surgery, University of Maryland Medical Center, 22 S. Greene Street, S8B02, Baltimore, MD 21201, U.S.A. Tel: +1 8574729182, Fax: +14103280401, e-mail: mseaton@som.umaryland.edu

Key Words: Aspirin, colorectal cancer, cardiovascular disease, polypectomy, Women's Health Initiative, chemoprevention. among elderly patients was recently linked to an overall higher risk of cancer (8). Aspirin therapy for CRC prevention should, therefore, be limited to individuals with a favorable risk-benefit ratio.

In 2016, the U.S. Preventive Services Task Force (USPSTF) recommended aspirin use for the primary prevention of both cardiovascular disease (CVD) and CRC in adults aged 50 to 59 years who are at high risk for CVD and an average risk for bleeding (9). CRC shares several risk factors with CVD $(10,11)$, including older age, male sex, smoking, diabetes, and obesity (10-12), so individuals with high CVD-risk likely also have high CRC risk. Many of the clinical trials that have established the association between aspirin use and CRC $(2,3)$ were designed to investigate the cardioprotective effects of aspirin and included only high CVD-risk populations (13-18). Therefore, it is unclear if individuals with different levels of CVD risk experience the chemopreventive effects of aspirin.

An important risk factor for CRC is a prior history of a colorectal adenoma (19), as most CRC develops through the adenoma-to-carcinoma sequence (12). Adenomas are frequently identified endoscopically and managed by polypectomy. In a randomized controlled trial, regular aspirin use lowered the risk of adenomas in patients with a history of CRC (20). Similarly, a meta-analysis of randomized trials found that aspirin lowered the risk of adenomas in patients with a history of adenomas (21). A family history of CRC is another known risk factor for CRC (22).

The purpose of this study was to evaluate the potential effect modification of CRC risk factors (CVD risk status, history of colorectal polypectomy, and family history of $\mathrm{CRC}$ ) on the association between aspirin use and CRC among post-menopausal women. We performed a stratified analysis of data from the Women's Health Initiative (WHI), a prospective study with detailed longitudinal data on postmenopausal women (23). 


\section{Patients and Methods}

The WHI is a large clinical investigation of common diseases affecting postmenopausal women, including cancer, CVD, and osteoporosis (23). The study was performed between 1995 and 2005 , with two extended follow-up periods $(2005-2010,2010$ 2020) for some participants (24). A total of 161,808 women aged 50 to 79 years were included in an observational study (OS) or one or more clinical trials (CT) investigating hormone therapy, diet modifications, and vitamin supplementation (24). Details of the WHI study design and methods have been previously described (24).

In this analysis, we included participants from both the OS and CT. We excluded participants with a history of CVD or CRC, those who developed CVD or CRC within 3 years of study enrollment, and those missing data required for CVD risk stratification. Regular aspirin use was defined as any dose taken $\geq 2$ times per week at study enrollment (baseline) and at the 3-year follow-up visit.

Underlying CVD risk was estimated by the non-laboratory based Framingham Risk Score, which was developed from the Framingham Heart Study (11). This risk score uses the following baseline participant characteristics: age, systolic blood pressure, hypertension treatment (yes/no), current smoking, diabetes, and body mass index (BMI). The calculator estimated the 10-year risk of a CVD event, defined as coronary heart disease, stroke, peripheral vascular disease, or heart failure (11). Participants were classified as low/normal risk ( $<10 \%$ ten-year risk) or high-risk ( $\geq 10 \%$ ten-year risk). Family history of CRC was defined as any first-degree relative with a history of CRC. History of colonoscopy and polypectomy were reported by the participants at study enrollment.

Ascertainment and adjudication methods of cancer outcomes in the WHI have been previously described (25). Participants or nextof-kin reported cancer diagnoses on questionnaires annually in the OS or semiannually in the CT through 2005 and annually in both studies thereafter. Reported cancer events were verified by centrally trained physician adjudicators via review of medical records and pathology reports.

Multivariable Cox proportional hazards regression models were used to estimate hazard ratios (HR), 95\% confidence intervals (CI), and $p$-values for the associations between aspirin use and $\mathrm{CRC}$ incidence, with stratification by CVD risk status, family history of $\mathrm{CRC}$, and history of polypectomy. We were investigating aspirin use for primary prevention, so observations were censored at stroke, myocardial infarction, and death. All analyses were performed using Stata 14.2 (College Station, TX, USA).

\section{Results}

Patient characteristics. Among the 161,808 participants in the WHI, 33,296 met exclusion criteria, leaving 128,512 participants for analysis (Figure 1). Of these, $47 \%$ $(n=60,912)$ had high CVD-risk, 15\% $(n=19,133)$ had a family history of CRC, and $47 \%(n=60,532)$ had a history of a colonoscopy (Table I). Among women with a history of colonoscopy, $16 \%(n=9,896)$ also had a history of a polypectomy. Participant selection and stratification is described in Figure 1.
Of all the included participants, 12,763 (10\%) used aspirin. There were 1,820 (1.4\%) incident cases of CRC over a median follow-up of 17 years. Patient demographics and characteristics at study enrollment are described in Table I.

Risk factors for CRC. In multivariable Cox-proportional hazards regression, age, high CVD-risk status, and family history of CRC were independently associated with higher risk of CRC $(p<0.001)$ (Table II). Among the entire cohort, a history of polypectomy was not associated with CRC $\left(\mathrm{HR}_{\mathrm{adj}}=1.07 ; 95 \% \mathrm{CI}=0.91-1.26 ; p=0.414\right) \quad$ (Table II), however among women who had undergone a colonoscopy it was associated with an approximately $27 \%$ higher risk of $\mathrm{CRC}\left(\mathrm{HR}_{\mathrm{adj}}=1.27 ; 95 \% \mathrm{CI}=1.06-1.50 ; p=0.008\right)$. In the entire cohort, aspirin use was associated with an approximately $23 \%$ lower risk of $\mathrm{CRC}\left(\mathrm{HR}_{\mathrm{adj}}=0.77,95 \% \mathrm{CI}=0.65-0.90\right.$, $p=0.001$ ) (Table III).

Stratified analyses. CVD-RISK. Approximately 8\% $(n=5,361)$ of women in the low/normal CVD-risk cohort and $12 \%(n=7,402)$ of women in the high CVD-risk cohort used aspirin. In multivariable Cox-proportional hazards regression, aspirin use was associated with an approximately $28 \%$ lower risk of CRC in the low/normal CVD-risk cohort $\left(\mathrm{HR}_{\mathrm{adj}}=0.72 ; 95 \% \mathrm{CI}=0.54-0.96 ; p=0.025\right)$ and an approximately $21 \%$ lower risk of CRC in the high CVD-risk cohort $\left(\mathrm{HR}_{\mathrm{adj}}=0.79,95 \% \mathrm{CI}=0.65-0.96 ; p=0.017\right)$ (Table III).

Family history of CRC. Approximately $10 \%(\mathrm{n}=10,743)$ of women without a family history of CRC and $11 \%$ $(n=2,020)$ of women with a family history of CRC used aspirin. Of the 1,820 participants who developed CRC, $23 \%(n=338)$ had a family history of CRC. In multivariable Cox-proportional hazards regression, aspirin use was associated with an approximately $28 \%$ lower risk of CRC among women without a family history of CRC $\left(\mathrm{HR}_{\mathrm{adj}}=0.72 ; 95 \% \mathrm{CI}=0.60-0.86 ; p<0.001\right) \quad($ Table III $)$. Aspirin use was not associated with risk of CRC in women who had a family history of $\mathrm{CRC} \quad\left(\mathrm{HR}_{\mathrm{adj}}=0.97\right.$; 95\% CI=0.70-1.36; $p=0.882$ ) (Table III).

History of polpyectomy. In the subgroup of 60,532 women with a history of a colonoscopy, $11 \%(n=5,699)$ of those who did not have a polypectomy and $12 \%(n=1,142)$ of those who did have a polypectomy used aspirin. In multivariable Coxproportional hazards regression, aspirin use was not associated with the risk of CRC among women who did not have a polypectomy $\left(\mathrm{HR}_{\mathrm{adj}}=0.90 ; 95 \% \mathrm{CI}=0.70-1.15\right.$, $p=0.398)$, however it was associated with approximately $48 \%$ lower risk of CRC among women who had a polypectomy $\left(\mathrm{HR}_{\mathrm{adj}}=0.52 ; 95 \% \mathrm{CI}=0.29-0.93 ; p=0.028\right)$ (Table III). 


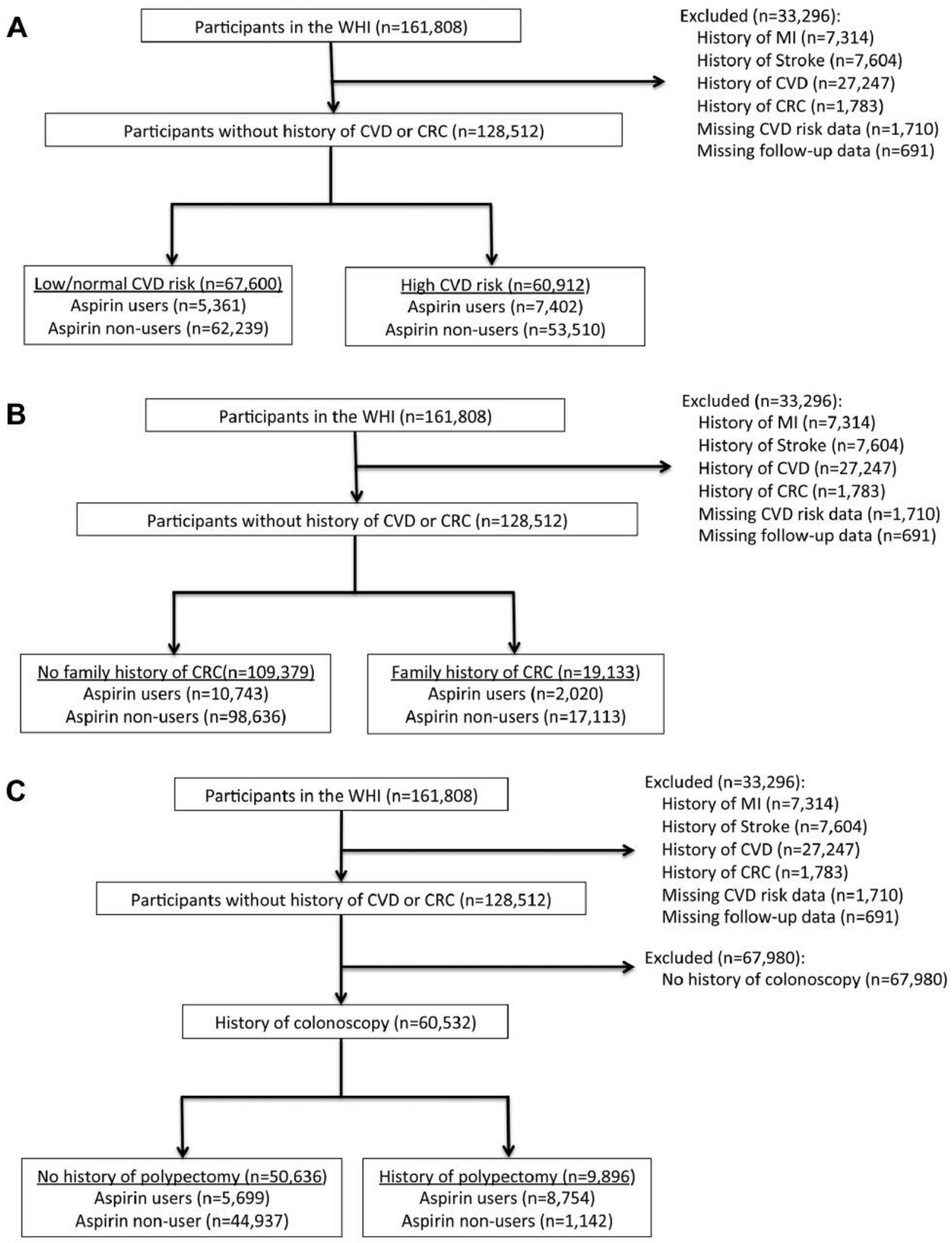

Figure 1. Consort. A) Stratification by CVD risk status. B) Stratification by family history of colorectal cancer. C) Stratification by history of colorectal polypectomy. WHI: Women's Health Initiative; MI: myocardial infarction; CVD: cardiovascular disease; CRC: colorectal cancer. 
Table I. Baseline patient demographics and characteristics, by aspirin use status.

\begin{tabular}{|c|c|c|c|}
\hline & All participants $(n=128,512)$ & Aspirin non-users $(\mathrm{n}=115,749)$ & Aspirin users $(n=12,763)$ \\
\hline \multicolumn{4}{|l|}{ Age, n (\%) } \\
\hline$<60$ & $45,993(36)$ & $43,014(37)$ & $2,979(23)$ \\
\hline $60-69$ & $57,417(45)$ & $51,096(44)$ & $6,321(50)$ \\
\hline$\geq 70$ & $25,102(20)$ & $21,639(19)$ & $3,463(27)$ \\
\hline \multicolumn{4}{|l|}{ Race/Ethnicity, n (\%) } \\
\hline White/Other & $117,365(91)$ & $105,163(91)$ & $12,202(96)$ \\
\hline Black/African American & $11,147(9)$ & $10,586(9)$ & $561(4)$ \\
\hline BMI, median (IQR) & $27(24,31)$ & $27(24,31)$ & $27(24,31)$ \\
\hline Systolic blood pressure, median (IQR) & $125(114,138)$ & $125(114,137)$ & $128(117,140)$ \\
\hline Treatment for hypertension, $\mathrm{n}(\%)$ & $27,896(22)$ & $24,143(21)$ & $3,753(29)$ \\
\hline Diabetes mellitus, n (\%) & $6,179(5)$ & $5,486(5)$ & $693(5)$ \\
\hline Current smoking, $\mathrm{n}(\%)$ & $8,759(7)$ & $8,063(7)$ & $696(6)$ \\
\hline CVD risk (\%), median (IQR) & $10(6,15)$ & $9(6,15)$ & $11(8,17)$ \\
\hline \multicolumn{4}{|l|}{ CVD risk, $\mathrm{n}(\%)$} \\
\hline Low/normal & $67,600(53)$ & $62,239(54)$ & $5,361(42)$ \\
\hline High & $60,912(47)$ & $53,510(46)$ & $7,402(58)$ \\
\hline Family history of CRC, $\mathrm{n}(\%)$ & $19,133(15)$ & $17,113(15)$ & $2,020(16)$ \\
\hline History of colonoscopy, $\mathrm{n}(\%)$ & $60,532(47)$ & $53,691(46)$ & $6,841(54)$ \\
\hline History of polypectomy, n (\%) & $9,896(8)$ & $8,754(8)$ & $1,142(9)$ \\
\hline
\end{tabular}

BMI: Body mass index; IQR: interquartile range; CVD: cardiovascular disease; CRC: colorectal cancer.

\section{Discussion}

Meta-analyses of observational and clinical trials have established that regular aspirin use significantly reduces the risk $\operatorname{CRC}(2,3,26)$. Aspirin is currently the most promising agent for primary CRC prevention $(4,27)$; it has the potential to prevent an estimated 29,800 CRC cases per year (28).

In 2016, the U.S. Preventive Services Task Force (USPSTF) was the first organization to recommend aspirin use for the primary prevention of both CVD and CRC (9). In their comprehensive analysis, the combined benefit of CVD and CRC prevention outweighed the risks of aspirin use only in individuals with high CVD-risk. The American Heart Association (AHA) / American Stroke Association (29) and the American Diabetes Association (30) do not recommend aspirin use for any individuals without high CVD-risk, however these recommendations do not take into account any concomitant effect on CRC risk. Currently, no organization recommends aspirin use solely for CRC prevention among the general population. For patients with Lynch syndrome who have a $52-82 \%$ lifetime risk of CRC, the National Comprehensive Cancer Network (NCCN) suggests aspirin use for chemoprevention (31).

In this study, we found that high CVD-risk was associated with a higher risk of CRC. We also showed that women with both low/normal and high CVD-risk who used aspirin had a lower risk of CRC compared to those who did not. This is consistent with prior reports. An analysis of the Nurses' Health Study and the Health Professionals Follow-up Study
Table II. Hazard ratios for colorectal cancer. Multivariable Cox proportional hazards regression with colorectal cancer as the outcome.

\begin{tabular}{lcc}
\hline & $\mathrm{HR}_{\text {adj }}(95 \% \mathrm{CI})$ & $p$-Value \\
\hline Age & & \\
$<60$ & Reference & \\
$60-69$ & $1.71(1.51,1.93)$ & $<0.001$ \\
$\geq 70$ & $2.36(2.03,2.74)$ & $<0.001$ \\
CVD risk & Reference & \\
$\quad$ Low/normal & $1.37(1.23,1.52)$ & $<0.001$ \\
$\quad$ High & & \\
Family history of CRC & Reference & \\
$\quad$ No & $1.24(1.10,1.40)$ & $<0.001$ \\
$\quad$ Yes & Reference & \\
History of colorectal polypectomy & $1.07(0.91,1.26)$ & 0.414 \\
$\quad$ No & & \\
Yes &
\end{tabular}

HR: Hazard ratio; CI: confidence interval; CVD: cardiovascular disease; CRC: colorectal cancer.

found that having $\geq 2$ cardiac risk factors did not modify the association between aspirin use and CRC risk (28). In addition, a microsimulation model performed by the USPSTF suggested that aspirin use reduces the risk of CRC at all CVD risk levels (32).

On the other hand, the recently published Aspirin in Reducing Events in the Elderly (ASPREE) trial $(7,8,33$ ) suggests that aspirin use is harmful in healthy older adults. This trial randomized adults aged 70 years or older (or $\geq 65$ 
Table III. Hazard ratios for colorectal cancer according to aspirin use status, stratified by colorectal cancer risk factors.

\begin{tabular}{|c|c|c|c|}
\hline Risk strata & Aspirin use & $\mathrm{HR}_{\mathrm{adj}}(95 \% \mathrm{CI})$ & $p$-Value \\
\hline \multirow[t]{2}{*}{ All participants } & No & Reference* & -- \\
\hline & Yes & $0.77(0.65,0.90)$ & 0.001 \\
\hline \multirow{2}{*}{ Low/normal CVD-risk } & No & Reference $^{\dagger}$ & -- \\
\hline & Yes & $0.72(0.54,0.96)$ & 0.025 \\
\hline \multirow[t]{2}{*}{ High CVD-risk } & No & Reference ${ }^{\dagger}$ & -- \\
\hline & Yes & $0.79(0.65,0.96)$ & 0.017 \\
\hline \multirow[t]{2}{*}{ No family history of CRC } & No & Reference & -- \\
\hline & Yes & $0.72(0.60,0.86)$ & $<0.001$ \\
\hline \multirow{2}{*}{ Family history of CRC } & No & Reference $¥$ & -- \\
\hline & Yes & $0.97(0.70,1.36)$ & 0.882 \\
\hline \multirow[t]{2}{*}{ History of colonoscopy without polypectomy } & No & Reference ${ }^{\#}$ & -- \\
\hline & Yes & $0.90(0.70,1.15)$ & 0.398 \\
\hline \multirow[t]{2}{*}{ History of colonoscopy with polypectomy } & No & Reference $\#$ & -- \\
\hline & Yes & $0.52(0.29,0.93)$ & 0.028 \\
\hline
\end{tabular}

HR: Hazard ratio; CI: confidence Interval; CVD: cardiovascular disease; CRC: colorectal cancer. *Adjusted for age, CVD risk, family history of $\mathrm{CRC}$, and history of polypectomy; ${ }^{\dagger}$ Adjusted for age, family history, and history of polypectomy; $¥$ Adjusted for age, CVD risk, and history of polypectomy; \#Adjusted for age, CVD risk, and family history of CRC.

years among blacks and Hispanics) without a history of CVD, dementia, or disability, to receive $100 \mathrm{mg}$ of aspirin daily or placebo. The aspirin cohort had higher incidence of death from any cause $(\mathrm{HR}=1.14,95 \% \mathrm{CI}=1.01-1.29)$, primarily due to higher cancer mortality $(\mathrm{HR}=1.31$, 95\% CI $=1.10-1.56)$, including $\mathrm{CRC}(\mathrm{HR}=1.77,95 \% \mathrm{CI}=1.02$ 3.06) (33). Aspirin use was also associated with a higher risk of major hemorrhage $(\mathrm{HR}=1.38 ; 95 \% \mathrm{CI}=1.18-1.62$; $p<0.001$ ) (7). Aspirin use for CRC prevention must therefore be weighed against the likelihood of these potential complications and the appropriate risk stratification employed to identify individuals who will have the greatest overall benefit.

In this study, a family history of CRC was associated with a higher risk of $\mathrm{CRC}$, but aspirin use among women in this subgroup was not associated with lower CRC risk $\left(\mathrm{HR}_{\mathrm{adj}}=0.97 ; 95 \% \mathrm{CI}=0.70-1.36 ; p=0.882\right)$. This is consistent with an analysis of the National Institutes of Health-AARP Diet and Health Study that found that aspirin use was not associated with a lower risk of CRC among patients with a first-degree relative with a history of colon cancer (34). In another study, NSAID use was associated with a lower risk of CRC among individuals with a family history of CRC $(\mathrm{OR}=0.4,95 \% \mathrm{CI}=0.2-0.9) \quad(35)$. Clinical trials by the Colorectal Adenoma/Carcinoma Prevention Program found that aspirin use had no effect on adenoma burden in patients with familial adenomatosis polyposis (FAP) (36), however it was associated with lower long-term risk of CRC in patients with Lynch syndrome (37). Whether aspirin use decreases $\mathrm{CRC}$ risk among all patients with a family history of CRC remains unclear, and we did not find evidence to support its use in this patient population.
In women with a history of colonoscopic polypectomy, aspirin use was associated with a lower risk of CRC. This is consistent with results of prior investigations of aspirin for the secondary prevention of colorectal neoplasms. In three clinical trials involving patients with a history of colorectal adenomas, aspirin use lowered the risk of recurrent adenomas (38-40). In another trial that included patients with a prior CRC that had been curatively resected, aspirin use lowered the risk of developing a new polyp $\left(\mathrm{HR}_{\mathrm{adj}}=0.64\right.$, 95\% CI $=0.43-0.94 ; p=0.022)(20)$.

Strengths of this study include the large cohort size, detailed data regarding CVD risk factors, long follow-up duration, and adjudicated cancer outcomes in the WHI. Our study had several limitations. First, we could not assess the risk of aspirin-related complications, including gastrointestinal (GI) and intracranial hemorrhage, because these data were not collected in the WHI. Previous studies have found that the risk of gastrointestinal complications is highest within the first weeks of starting aspirin and decreases with continued aspirin use (41). In this study, the duration of aspirin use was at least 3 years, so there was likely a relatively low incidence of GI complications as therapy likely would have been discontinued if significant adverse effects occurred. In addition, we used a generalized definition of regular aspirin use (any dose used $\geq 2$ times per week at study enrollment and at the year 3 followup visit), so variations in dosage, frequency of use, and duration were not considered. A recent study found that current users of aspirin, regardless of dose, had a significantly reduced risk of CRC (42). Other studies have found that at least 10 years of use are required for a chemo-preventative benefit (43). Although aspirin use in our study included a range of dosages, frequencies, and durations, the $23 \%$ risk 
reduction in the non-stratified analysis was remarkably similar in magnitude to the $24 \%$ risk reduction found in a pooled analysis of four clinical trials $(\mathrm{HR}=0.76,95 \% \mathrm{CI}=0.60-0.96$, $p=0.02$ ) (3). Another potential limitation of this study was the use of the non-laboratory based Framingham Risk Score rather than the commonly used American College of Cardiology (ACC)/AHA risk calculator (10). We used the non-laboratorybased Framingham Risk Score because only a fraction of the selected WHI participants had the serum lipid measurements required for the ACC/AHA risk calculator. Finally, polypectomy data were self-reported by the study participants and were not adjudicated, and the histopathology of the polyps was not known.

\section{Conclusion}

In our analysis of the WHI, high CVD-risk and a family history of CRC were both independently associated with higher risk of CRC. Among women who had a prior colonoscopy, a polypectomy was also associated with a higher risk of CRC. Aspirin use was associated with a lower risk of CRC among women with low/normal or high CVDrisk, no family history of CRC, or a history of colonoscopy with polypectomy. Aspirin use was not associated with CRC risk in women with a family history of CRC or a history of colonoscopy without polypectomy. Additional prospective trials that also evaluate complications of therapy are needed to confirm the effects of aspirin on CRC risk in these subgroups of women, as well as guide future treatment recommendations.

\section{Conflicts of Interest}

The Authors have no conflicts of interest regarding this study.

\section{Authors' Contributions}

N.Z. and U.P. jointly conceived the study. N.Z., U.P., C.K., K.C.J., and M.E.S. designed the analysis. M.E.S. and C.K. performed the analysis. M.E.S. wrote the manuscript. K.C.J. and A.B. gave substantial conceptual advice and edited the manuscript. All Authors discussed the results of the study, made comments on the manuscript, and gave final approval of the version to be published.

\section{Acknowledgements}

The WHI program is funded by the National Heart, Lung, and Blood Institute, National Institutes of Health, U.S. Department of Health and Human Services through contracts HHSN268201100046C, HHSN268201100001C, HHSN268201100002C, HHSN268201100 003C, HHSN268201100004C, and HHSN271201100004C.

The Authors would like to thank the WHI participants who made this study possible. The Authors would also like to thank the WHI coordinators: Program Office: (National Heart, Lung, and Blood Institute, Bethesda, MD, USA) Jacques Rossouw, Shari Ludlam,
Dale Burwen, Joan McGowan, Leslie Ford, and Nancy Geller; Clinical Coordinating Center: (Fred Hutchinson Cancer Research Center, Seattle, WA, USA) Garnet Anderson, Ross Prentice, Andrea LaCroix, and Charles Kooperberg Investigators and Academic Centers: (Brigham and Women's Hospital, Harvard Medical School, Boston, MA, USA) JoAnn E. Manson; (MedStar Health Research Institute/Howard University, Washington, DC, USA) Barbara V. Howard; (Stanford Prevention Research Center, Stanford, CA, USA) Marcia L. Stefanick; (The Ohio State University, Columbus, $\mathrm{OH}$, USA) Rebecca Jackson; (University of Arizona, Tucson/Phoenix, AZ, USA) Cynthia A. Thomson; (University at Buffalo, Buffalo, NY, USA) Jean Wactawski-Wende; (University of Florida, Gainesville/Jacksonville, FL, USA) Marian Limacher; (University of Iowa, Iowa City/Davenport, IA, USA) Robert Wallace; (University of Pittsburgh, Pittsburgh, PA, USA) Lewis Kuller; (Wake Forest University School of Medicine, WinstonSalem, NC, USA) Sally Shumaker; Women's Health Initiative Memory Study: (Wake Forest University School of Medicine, Winston-Salem, NC, USA) Sally Shumaker.

\section{References}

1 Bray F, Ferlay J, Soerjomataram I, Siegel RL, Torre LA and Jemal A: Global cancer statistics 2018: Globocan estimates of incidence and mortality worldwide for 36 cancers in 185 countries. CA Cancer J Clin 68(6): 394-424, 2018. PMID: 30207593. DOI: $10.3322 /$ caac. 21492

2 Flossmann E and Rothwell PM: Effect of aspirin on long-term risk of colorectal cancer: Consistent evidence from randomised and observational studies. Lancet 369(9573): 1603-1613, 2007. PMID: 17499602. DOI: 10.1016/S0140-6736(07)60747-8

3 Rothwell PM, Wilson M, Elwin CE, Norrving B, Algra A, Warlow CP and Meade TW: Long-term effect of aspirin on colorectal cancer incidence and mortality: 20-year follow-up of five randomised trials. Lancet 376(9754): 1741-1750, 2010. PMID: 20970847. DOI: 10.1016/S0140-6736(10)61543-7

4 Chan AT, Arber N, Burn J, Chia WK, Elwood P, Hull MA, Logan RF, Rothwell PM, Schror K and Baron JA: Aspirin in the chemoprevention of colorectal neoplasia: An overview. Cancer Prev Res (Phila) 5(2): 164-178, 2012. PMID: 22084361. DOI: 10.1158/1940-6207.CAPR-11-0391

5 Ranger GS: Current concepts in colorectal cancer prevention with cyclooxygenase inhibitors. Anticancer Res 34(11): 62776282, 2014. PMID: 25368225.

6 Whitlock EP, Williams SB, Burda BU, Feightner A and Beil T: U.S. Preventive services task force evidence syntheses, formerly systematic evidence reviews. In: Aspirin use in adults: Cancer, allcause mortality, and harms: A systematic evidence review for the us preventive services task force. Agency for Healthcare Research and Quality (US): Rockville (MD), 2015. PMID: 26491756.

7 McNeil JJ, Wolfe R, Woods RL, Tonkin AM, Donnan GA, Nelson MR, Reid CM, Lockery JE, Kirpach B, Storey E, Shah RC, Williamson JD, Margolis KL, Ernst ME, Abhayaratna WP, Stocks N, Fitzgerald SM, Orchard SG, Trevaks RE, Beilin LJ, Johnston CI, Ryan J, Radziszewska B, Jelinek M, Malik M, Eaton CB, Brauer D, Cloud G, Wood EM, Mahady SE, Satterfield S, Grimm R and Murray AM: Effect of aspirin on cardiovascular events and bleeding in the healthy elderly. N Engl J Med 379(16): 1509-1518, 2018. PMID: 30221597. DOI: 10.1056/NEJMoa1805819 
8 McNeil JJ, Woods RL, Nelson MR, Reid CM, Kirpach B, Wolfe R, Storey E, Shah RC, Lockery JE, Tonkin AM, Newman AB, Williamson JD, Margolis KL, Ernst ME, Abhayaratna WP, Stocks N, Fitzgerald SM, Orchard SG, Trevaks RE, Beilin LJ, Donnan GA, Gibbs P, Johnston CI, Ryan J, Radziszewska B, Grimm R and Murray AM: Effect of aspirin on disability-free survival in the healthy elderly. N Engl J Med 379(16): 1499-1508, 2018. PMID: 30221596. DOI: 10.1056/NEJMoa1800722

9 Bibbins-Domingo K: Aspirin use for the primary prevention of cardiovascular disease and colorectal cancer: U.S. Preventive services task force recommendation statement. Ann Intern Med 164(12): 836-845, 2016. PMID: 27064677. DOI: 10.7326/M160577

10 Goff DC Jr., Lloyd-Jones DM, Bennett G, Coady S, D’Agostino RB Sr., Gibbons R, Greenland P, Lackland DT, Levy D, O'Donnell CJ, Robinson JG, Schwartz JS, Shero ST, Smith SC Jr., Sorlie P, Stone NJ and Wilson PW: 2013 ACC/AHA guideline on the assessment of cardiovascular risk: A report of the American College of Cardiology/American Heart Association task force on practice guidelines. J Am Coll Cardiol 63(25 Pt B): 2935-2959, 2014. PMID: 24239921. DOI: 10.1016/j.jacc.2013. 11.005

11 D'Agostino RB, Sr., Vasan RS, Pencina MJ, Wolf PA, Cobain M, Massaro JM and Kannel WB: General cardiovascular risk profile for use in primary care: The Framingham Heart Study. Circulation 117(6): 743-753, 2008. PMID: 18212285. DOI: 10.1161/CIRCULATIONAHA.107.699579

12 Brenner H, Kloor M and Pox CP: Colorectal cancer. Lancet 383(9927): 1490-1502, 2014. PMID: 24225001. DOI: 10.1016/S0140-6736(13)61649-9

13 Juul-Moller S, Edvardsson N, Jahnmatz B, Rosen A, Sorensen $\mathrm{S}$ and Omblus R: Double-blind trial of aspirin in primary prevention of myocardial infarction in patients with stable chronic angina pectoris. The Swedish Angina Pectoris Aspirin Trial (SAPAT) group. Lancet 340(8833): 1421-1425, 1992. PMID: 1360557. DOI: 10.1016/0140-6736(92)92619-q

14 Aspirin effects on mortality and morbidity in patients with diabetes mellitus. Early treatment diabetic retinopathy study report 14. ETDRS investigators. Jama 268(10): 1292-1300, 1992. PMID: 1507375. DOI: 10.1001/jama.1992.034 90100090033

15 Belch J, MacCuish A, Campbell I, Cobbe S, Taylor R, Prescott R, Lee R, Bancroft J, MacEwan S, Shepherd J, Macfarlane P, Morris A, Jung R, Kelly C, Connacher A, Peden N, Jamieson A, Matthews D, Leese G, McKnight J, O’Brien I, Semple C, Petrie J, Gordon D, Pringle S and MacWalter R: The prevention of progression of arterial disease and diabetes (popadad) trial: Factorial randomised placebo controlled trial of aspirin and antioxidants in patients with diabetes and asymptomatic peripheral arterial disease. Bmj 337: a1840, 2008. PMID: 18927173. DOI: $10.1136 / \mathrm{bmj} . \mathrm{a} 1840$

16 Fowkes FG, Price JF, Stewart MC, Butcher I, Leng GC, Pell AC, Sandercock PA, Fox KA, Lowe GD and Murray GD: Aspirin for prevention of cardiovascular events in a general population screened for a low ankle brachial index: A randomized controlled trial. Jama 303(9): 841-848, 2010. PMID: 20197530. DOI: $10.1001 /$ jama.2010.221

17 Farrell B, Godwin J, Richards S and Warlow C: The United Kingdom transient ischaemic attack (UK-TIA) aspirin trial: Final results. J Neurol Neurosurg Psychiatry 54(12): 1044-1054, 1991. PMID: 1783914. DOI: 10.1136/jnnp.54.12.1044
18 Thrombosis prevention trial: Randomised trial of low-intensity oral anticoagulation with warfarin and low-dose aspirin in the primary prevention of ischaemic heart disease in men at increased risk. The medical research council's general practice research framework. Lancet 351(9098): 233-241, 1998. PMID: 9457092.

19 Coleman HG, Loughrey MB, Murray LJ, Johnston BT, Gavin AT, Shrubsole MJ, Bhat SK, Allen PB, McConnell V and Cantwell MM: Colorectal cancer risk following adenoma removal: A large prospective population-based cohort study. Cancer Epidemiol Biomarkers Prev 24(9): 1373-1380, 2015. PMID: 26082403. DOI: 10.1158/1055-9965.EPI-15-0085

20 Sandler RS, Halabi S, Baron JA, Budinger S, Paskett E, Keresztes R, Petrelli N, Pipas JM, Karp DD, Loprinzi CL, Steinbach $G$ and Schilsky R: A randomized trial of aspirin to prevent colorectal adenomas in patients with previous colorectal cancer. N Engl J Med 348(10): 883-890, 2003. PMID: 12621132. DOI: 10.1056/NEJMoa021633

21 Cole BF, Logan RF, Halabi S, Benamouzig R, Sandler RS, Grainge MJ, Chaussade S and Baron JA: Aspirin for the chemoprevention of colorectal adenomas: Meta-analysis of the randomized trials. J Natl Cancer Inst 101(4): 256-266, 2009. PMID: 19211452. DOI: $10.1093 /$ jnci/djn485

22 Fuchs CS, Giovannucci EL, Colditz GA, Hunter DJ, Speizer FE and Willett WC: A prospective study of family history and the risk of colorectal cancer. N Engl J Med 331(25): 1669-1674, 1994. PMID: 7969357. DOI: 10.1056/NEJM199412223312501

23 Design of the women's health initiative clinical trial and observational study. The Women's Health Initiative study group. Control Clin Trials 19(1): 61-109, 1998. PMID: 9492970.

24 Anderson GL, Manson J, Wallace R, Lund B, Hall D, Davis S, Shumaker S, Wang CY, Stein E and Prentice RL: Implementation of the Women's Health Initiative study design. Ann Epidemiol 13(9 Suppl): S5-17, 2003. PMID: 14575938.

25 Curb JD, McTiernan A, Heckbert SR, Kooperberg C, Stanford J, Nevitt M, Johnson KC, Proulx-Burns L, Pastore L, Criqui M and Daugherty S: Outcomes ascertainment and adjudication methods in the women's health initiative. Ann Epidemiol $13(9$ Suppl): S122-128, 2003. PMID: 14575944.

26 Algra AM and Rothwell PM: Effects of regular aspirin on longterm cancer incidence and metastasis: A systematic comparison of evidence from observational studies versus randomised trials. Lancet Oncol 13(5): 518-527, 2012. PMID: 22440112. DOI:10. 1016/S1470-2045(12)70112-2

27 Drew DA, Cao Y and Chan AT: Aspirin and colorectal cancer: The promise of precision chemoprevention. Nat Rev Cancer 16(3): 173-186, 2016. PMID: 26868177. DOI: 10.1038/nrc. 2016.4

28 Cao Y, Nishihara R, Wu K, Wang M, Ogino S, Willett WC, Spiegelman D, Fuchs CS, Giovannucci EL and Chan AT: Population-wide impact of long-term use of aspirin and the risk for cancer. JAMA Oncol 2(6): 762-769, 2016. PMID: 26940135. DOI: 10.1001/jamaoncol.2015.6396

29 Goldstein LB, Bushnell CD, Adams RJ, Appel LJ, Braun LT, Chaturvedi S, Creager MA, Culebras A, Eckel RH, Hart RG, Hinchey JA, Howard VJ, Jauch EC, Levine SR, Meschia JF, Moore WS, Nixon JV and Pearson TA: Guidelines for the primary prevention of stroke: A guideline for healthcare professionals from the American Heart Association/American Stroke Association. Stroke 42(2): 517-584, 2011. PMID: 21127304. DOI: 10.1161/STR.0b013e3181fcb238 
30 Pignone M, Alberts MJ, Colwell JA, Cushman M, Inzucchi SE, Mukherjee D, Rosenson RS, Williams CD, Wilson PW and Kirkman MS: Aspirin for primary prevention of cardiovascular events in people with diabetes: A position statement of the American Diabetes Association, a scientific statement of the American Heart Association, and an expert consensus document of the American College of Cardiology foundation. Diabetes Care 33(6): 1395-1402, 2010. PMID: 20508233. DOI: 10.2337/ dc10-0555

31 Benson AB, 3rd, Venook AP, Cederquist L, Chan E, Chen YJ, Cooper HS, Deming D, Engstrom PF, Enzinger PC, Fichera A, Grem JL, Grothey A, Hochster HS, Hoffe S, Hunt S, Kamel A, Kirilcuk N, Krishnamurthi S, Messersmith WA, Mulcahy MF, Murphy JD, Nurkin S, Saltz L, Sharma S, Shibata D, Skibber JM, Sofocleous CT, Stoffel EM, Stotsky-Himelfarb E, Willett CG, Wu CS, Gregory KM and Freedman-Cass D: Colon cancer, version 1.2017, NCCN Clinical Practice Guidelines in Oncology. J Natl Compr Canc Netw 15(3): 370-398, 2017. PMID: 28275037.

32 Dehmer SP, Maciosek MV and Flottemesch TJ: U.S. Preventive services task force evidence syntheses, formerly systematic evidence reviews. In: Aspirin use to prevent cardiovascular disease and colorectal cancer: A decision analysis: Technical report. Agency for Healthcare Research and Quality (US): Rockville (MD), 2015. PMID: 26491755.

33 McNeil JJ, Nelson MR, Woods RL, Lockery JE, Wolfe R, Reid CM, Kirpach B, Shah RC, Ives DG, Storey E, Ryan J, Tonkin AM, Newman AB, Williamson JD, Margolis KL, Ernst ME, Abhayaratna WP, Stocks N, Fitzgerald SM, Orchard SG, Trevaks RE, Beilin LJ, Donnan GA, Gibbs P, Johnston CI, Radziszewska B, Grimm R and Murray AM: Effect of aspirin on all-cause mortality in the healthy elderly. N Engl J Med 379(16): 15191528, 2018. PMID: 30221595. DOI: 10.1056/NEJMoa1803955

34 Ruder EH, Laiyemo AO, Graubard BI, Hollenbeck AR, Schatzkin A and Cross AJ: Non-steroidal anti-inflammatory drugs and colorectal cancer risk in a large, prospective cohort. Am J Gastroenterol 106(7): 1340-1350, 2011. PMID: 21407185. DOI: $10.1038 /$ ajg.2011.38

35 Coogan PF, Rosenberg L, Louik C, Zauber AG, Stolley PD, Strom BL and Shapiro S: NSAIDs and risk of colorectal cancer according to presence or absence of family history of the disease. Cancer Causes Control 11(3): 249-255, 2000. PMID: 10782659 .

36 Burn J, Bishop DT, Chapman PD, Elliott F, Bertario L, Dunlop MG, Eccles D, Ellis A, Evans DG, Fodde R, Maher ER, Moslein G, Vasen HF, Coaker J, Phillips RK, Bulow S and Mathers JC: A randomized placebo-controlled prevention trial of aspirin and/or resistant starch in young people with familial adenomatous polyposis. Cancer Prev Res (Phila) 4(5): 655-665, 2011. PMID: 21543343. DOI: 10.1158/1940-6207.CAPR-11-0106
37 Burn J, Gerdes AM, Macrae F, Mecklin JP, Moeslein G, Olschwang S, Eccles D, Evans DG, Maher ER, Bertario L, Bisgaard ML, Dunlop MG, Ho JW, Hodgson SV, Lindblom A, Lubinski J, Morrison PJ, Murday V, Ramesar R, Side L, Scott RJ, Thomas HJ, Vasen HF, Barker G, Crawford G, Elliott F, Movahedi M, Pylvanainen K, Wijnen JT, Fodde R, Lynch HT, Mathers JC and Bishop DT: Long-term effect of aspirin on cancer risk in carriers of hereditary colorectal cancer: An analysis from the CAPP2 randomised controlled trial. Lancet 378(9809): 2081-2087, 2011. PMID: 22036019. DOI: 10.1016/ S0140-6736(11)61049-0

38 Logan RF, Grainge MJ, Shepherd VC, Armitage NC and Muir KR: Aspirin and folic acid for the prevention of recurrent colorectal adenomas. Gastroenterology 134(1): 29-38, 2008. PMID: 18022173. DOI: 10.1053/j.gastro.2007.10.014

39 Baron JA, Cole BF, Sandler RS, Haile RW, Ahnen D, Bresalier R, McKeown-Eyssen G, Summers RW, Rothstein R, Burke CA, Snover DC, Church TR, Allen JI, Beach M, Beck GJ, Bond JH, Byers T, Greenberg ER, Mandel JS, Marcon N, Mott LA, Pearson L, Saibil F and van Stolk RU: A randomized trial of aspirin to prevent colorectal adenomas. N Engl J Med 348(10): 891-899, 2003. PMID: 12621133. DOI: 10.1056/NEJMoa 021735

40 Benamouzig R, Deyra J, Martin A, Girard B, Jullian E, Piednoir B, Couturier D, Coste T, Little J and Chaussade S: Daily soluble aspirin and prevention of colorectal adenoma recurrence: Oneyear results of the apacc trial. Gastroenterology 125(2): 328-336, 2003. PMID: 12891533. DOI: 10.1016/s0016-5085(03)00887-4

41 Garcia Rodriguez LA, Hernandez-Diaz S and de Abajo FJ: Association between aspirin and upper gastrointestinal complications: Systematic review of epidemiologic studies. Br J Clin Pharmacol 52(5): 563-571, 2001. PMID: 11736865. DOI: 10.1046/j.0306-5251.2001.01476.x

42 Garcia Rodriguez LA, Soriano-Gabarro M, Bromley S, Lanas A and Cea Soriano L: New use of low-dose aspirin and risk of colorectal cancer by stage at diagnosis: A nested case-control study in UK general practice. BMC Cancer 17(1): 637, 2017. PMID: 28882113. DOI: 10.1186/s12885-017-3594-9

43 Collet JP, Sharpe C, Belzile E, Boivin JF, Hanley J and Abenhaim L: Colorectal cancer prevention by non-steroidal antiinflammatory drugs: Effects of dosage and timing. Br J Cancer 81(1): 62-68, 1999. PMID: 10487613. DOI: 10.1038/sj.bjc. 6690651 